\title{
Designing an Intelligent Teaching Simulator for Learning to Teach by Practicing
}

\author{
Vu Minh Chieu and Patricio Herbst ${ }^{1}$
}

\begin{abstract}
Learning to teach is difficult for prospective teachers because of the complex nature of the work of teaching. Practicing (Lampert 2010), interacting with the practice of teaching from a first-person perspective, may give them a unique experience in learning to teach. Computer-based simulators in which the apprentice teacher can interact with virtual students may be used to create that kind of experience. In this paper, we show how to apply techniques in artificial intelligence to design an intelligent learning environment. We show how to model the apprentice's decision-making and resources that can help him or her improve the practice of teaching.
\end{abstract}

Keywords: representation of teaching, teacher education, teaching simulator, intelligent tutoring system, mathematics education

\section{Introduction}

Teaching is a unique practice: Every instance of that practice is a performance that takes place over time, where the teacher needs to make strategic decisions, where $\mathrm{s} /$ he can seize or miss tactical opportunities, and where $\mathrm{s} / \mathrm{he}$ can use various kinds of resources (Lampert 2001; Shavelson 1983) to help students learn what s/he expects them to learn. Leinhardt and Ohlsson (1990) point out that "teaching is socially dynamic, ill structured, and extremely complex" (p. 22). In other words, the teacher often deals with highly variable situations from student to student, moment to moment, and class to class. One or few solutions are insufficient for the teacher to handle all situations. In addition, the problems of teaching are often hard to predict: novice teachers frequently meet problems in their practice that they have never met before (Lin, Schwartz, and Hatano 2005). Therefore, one of the important goals in teacher education is to help them develop

\footnotetext{
${ }^{1}$ Work reported in this article has been done with the support of the U. S. National Science Foundation through grant ESI-0353285 to P. Herbst. All opinions are those of the authors and do not necessarily reflect the views of the Foundation. Both authors contributed equally to this work.
} 
the ability to adapt themselves and their environment in response to a wide range of classroom and student variability (Lin 2001).

Different approaches to learning that focus on practice have been proposed and a variety of technologies have been implemented to attain the above objective. Fishman and Davis (2006) provide useful reviews of those approaches and technologies. Some of those are specific to learning the practice of teaching and Lampert (2010) provides a framework for learning teaching from practice.

Video records of classroom teaching are often used in those approaches to support teachers' learning to do practice; see for example, Lampert and Ball (1998), van Es and Sherin (2008). Indeed, video artifacts may sustain teachers' learning about, for example, subject matter or pedagogical knowledge (Wang and Hartley 2003), pedagogical content knowledge (Lampert and Ball 1998), and noticing (van Es and Sherin 2008).

Video records of classroom interaction have obviously provided teachers with useful learning experiences from a third-person perspective (i.e., to observe other teachers in action). There seems to be, however, a critical limitation of this kind of representations of teaching: it is very difficult for the apprentice teacher to practice alternative actions and get immediate feedback (e.g., to see students' reactions) in response to critical events while watching video records of classroom instruction. Also, it is obviously impossible for the apprentice to perform that kind of "try-and-see" experiences with real students in a real classroom. A number of virtual environments (e.g., Second Life: http://secondlife.com, Unreal Engine: http://unrealtechnology.com) or software pieces (e.g., The Teaching Simulator, see http://teachsim.com; or the lesson sketching software of project ThEMaT, see Herbst, Chazan, Chen, Chieu, and Weiss this issue) may provide platforms for that purpose. Indeed, based on those platforms or tools one can develop virtual environments in which the apprentice can interact with virtual agents or other apprentices who play the role of students. We argue, however, that while practicing teaching in that kind of virtual settings, the apprentice needs support or scaffolding to be able to learn how to practice effectively. We are interested in intelligent support that is automatically generated to tailor to the individual needs of the apprentice in a specific learning context. 
Accepted for publication at ZDM-The International Journal on Mathematics Education

Our contribution here aims at sketching and exemplifying the design of an intelligent computer-based simulation system, an interactive representation of teaching, that could provide significant help to overcome the previous limitation. An intelligent teaching simulator is a software in which the apprentice can interact with virtual students, freely make decisions, and receive immediate feedback from the system on his or her decisions (in the forms of reactions by virtual students or judgments by the system). We believe that such a simulator could provide apprentices with a unique and useful experience - to investigate the practice of teaching from a first-person perspective - an experience that is closer to the work of teaching they would eventually do in a real classroom. A simulator would allow them to get relevant, immediate, and multidimensional feedback from the system that helps them improve their professional practice, and they would not see any potential harm in interacting with virtual students.

The microteaching approach (Allen and Eve 1968) using complexity-reduced teaching contexts and video records of practice was an early attempt to create first-person engagements with practice. This approach can help the apprentice examine and reflect on his or her own professional practice and get feedback and comments from peers and instructors. Some research has documented the value (e.g., see Fernandez and Robinson 2006) and the limitations (e.g., see Macleod 1987) of microteaching. The simulation approach we propose pursues similar goals as microteaching: to reduce some complexity and enable reflection. Our approach also contributes the possibility of feeding researchbased knowledge about students' responses to instructional tasks into the problems the apprentice needs to handle through the actions of the virtual students. In working with the simulator we envision, the apprentice is more likely to encounter more cognitively demanding problems of practice than those that they may encounter when they microteach in front of their peers (where performative demands may be especially salient).

Computer-based simulations have been largely used in the professional education of practitioners other than teachers (Lajoie, Faremo, and Wiseman 2001). For example, Luengo and associates (Chieu, Luengo, Vadcard, and Tonetti in press; Luengo, MuftiAlchawafa, and Vadcard 2007) developed a simulation-based intelligent learning environment to support the novice surgeon in mastering pragmatic knowledge in the 
Accepted for publication at ZDM-The International Journal on Mathematics Education

domain of orthopedic surgery. Mulgund, Asdigha, Zacharias, Krishnakumar, and Dohme (1995) built a simulation-based intelligent flight trainer for the neophyte student to develop practical skills on a suite of initial entry rotary wing maneuvers.

In this paper, we show how to design an intelligent teaching simulator, which aims at helping apprentice teachers develop the ability to manage students' engagement in proving in geometry. We have chosen the instructional situation of doing proofs (Herbst and Brach 2006; Herbst, Chen, Weiss, and González 2009) because it provides a simple but sufficiently complex context to illustrate our approach, which we believe could be applied to other instructional situations as well. By instructional situation we mean a system of norms for interaction, usually tacit, that regulate how the teacher and students trade the work they do in and through classroom interaction in exchange for claims on having taught and learned the knowledge at stake. The situation "doing proofs" (Herbst, Chen, Weiss, and González 2009) consists of a set of norms that regulate the work that students and teacher do producing a proof of a specific proposition in such a way that the work can trade for the more general claim that students know how to do proofs. While situations organize classroom interaction into relatively stable, predictable patterns, they do not determine it - classroom interaction is complex not the least because individuals may depart from what they are expected to do. In particular when students depart from what they are expected to do this creates a problem of teaching in Lampert's (2001) sense - not an undesirable event that needs to be eliminated but a legitimate demand of the work that needs to be handled deliberately. The notion of practical rationality of mathematics teaching proposed by Herbst and Chazan (2003) after Bourdieu (1998) designates a set of categories of perception and appreciation with which experienced teachers handle departures from the norms of an instructional situation (see also Nachlieli and Herbst 2009). In the work presented here we illustrate how some of the dispositions of practical rationality could be learned in interaction with a simulator.

\section{Context for the Examples}

Let's assume that an apprentice confronts the following situation (adapted from Nachlieli and Herbst 2009): In a high school geometry class, students are given a sheet of paper in which a parallelogram had been drawn and were asked what happened with its 
angle bisectors. After students conjecture that the angle bisectors make a rectangle (Figure 1), the teacher encourages the class to prove that conjecture. The teacher draws the two-column form for statements and reasons (which the students had been accustomed in their earlier work). A student, Eamonn, volunteers to go to the board and lists what was given (e.g., $\mathrm{ABCD}$ is a parallelogram; $\overrightarrow{A L}$ bisects $\angle \mathrm{BAD}$ ). Then, Eamonn states that the angle bisectors of opposite angles in the parallelogram are parallel ( $\overleftrightarrow{A L} / / \overleftrightarrow{C J}$, see Figure 1). He pauses for a while, staring at the figure and at the two column form. It seems that he does not know what to say next. The apprentice is now asked to play the role of the teacher and figure out how to handle that event.

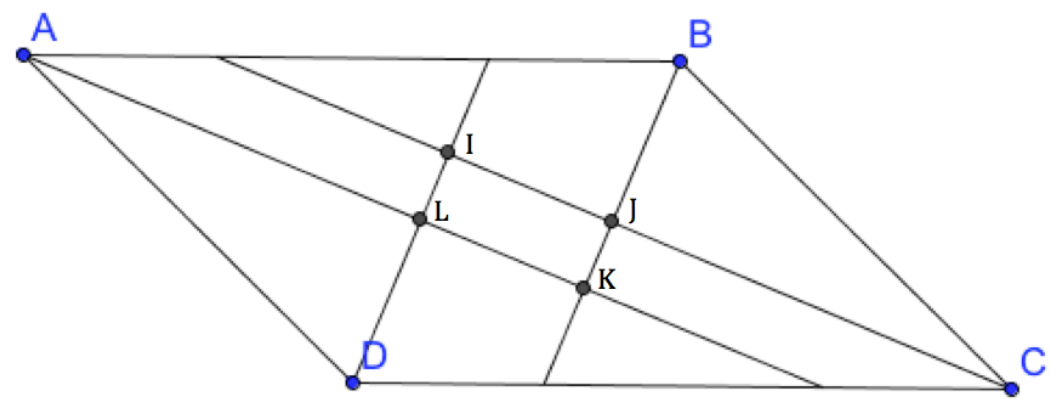

Figure 1. Angle bisectors of a parallelogram make a rectangle.

The apprentice needs to decide what to do next. The teaching simulator needs to be designed in a manner that allows the apprentice to express his or her decisions. It must be able to diagnose the conceptions about how to manage "doing proofs" behind those decisions. Finally, on the basis of the diagnosis result, the simulation system needs to be able to give relevant feedback on the apprentice's decisions to help him or her develop the ability to manage students doing proofs.

The design of such an intelligent teaching simulator has been inspired by the TELEOS (Technology Enhanced Learning Environment for Orthopedic Surgery) project directed by V. Luengo (Luengo, Mufti-Alchawafa, and Vadcard 2007). On the basis of didactical analysis results of apprenticeship settings, the TELEOS researchers built a 3-D intelligent simulation system that allows the apprentice surgeon to use a virtual pin to interact with a virtual pelvis object for the problem of sacro-iliac screw fixation, so as to develop professional practical skills. 


\section{System Architecture}

Figure 2 shows a global architecture of a simulation-based intelligent learning environment (a teaching simulator), adapted from the TELEOS architecture.

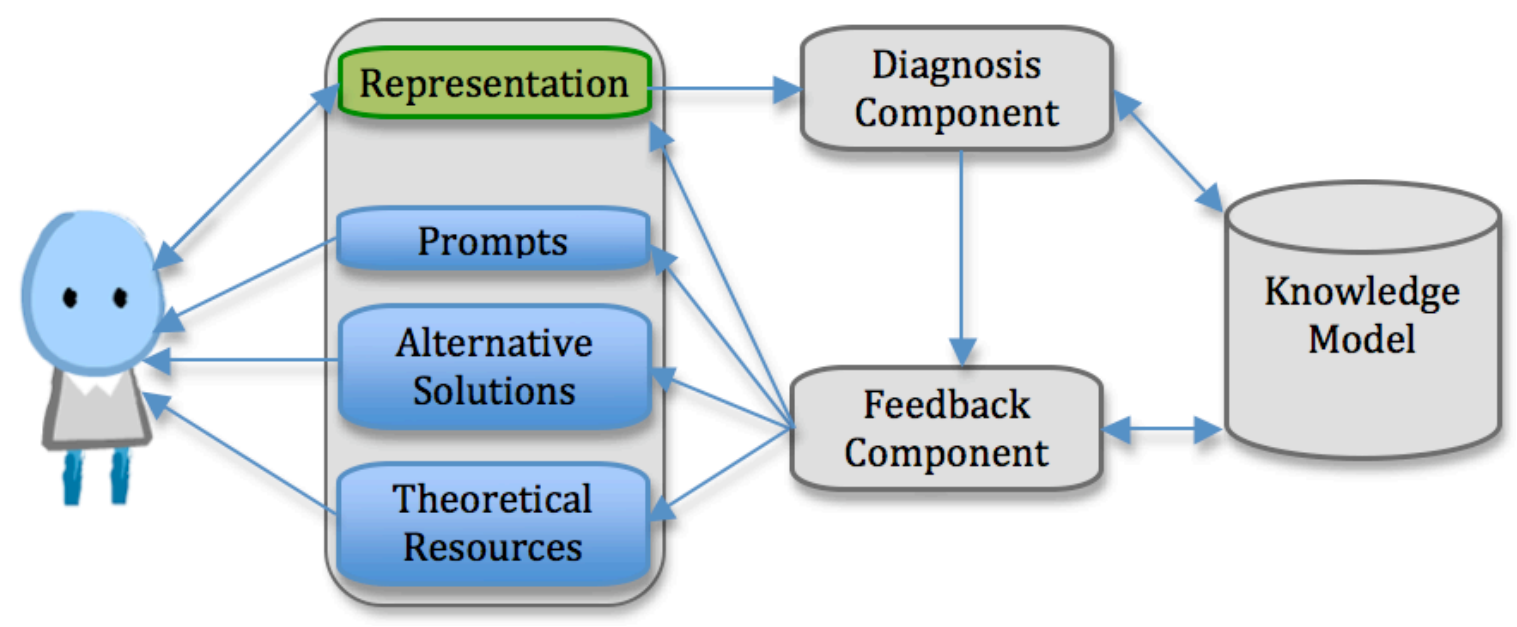

Figure 2. A global architecture of a teaching simulator.

The representation or user-interface component is a key part of the system to frame the learning context. It can be used to present problems of teaching, to receive the input from the user (i.e., his or her decisions), as well as to give feedback to the apprentice. It consists of a web-based lesson sketching tool designed in the context of project ThEMaT ${ }^{2}$ (see Herbst, Chazan, Chen, Chieu, and Weiss this issue; Chieu, Weiss, and Herbst 2009). The tool enables representations of lessons in the forms of graphicsbased slideshows (Figure 3). Each slide may consist of a classroom background, a cartoon teacher, a number of cartoon students, and props (e.g., compass). Facial expressions (e.g., confused, happy) and hand gestures (e.g., a low or high position) of those characters can be customized. Text-based dialogs in different forms (e.g., talking, shouting) can also be put into a slide. Whiteboard content can be added and edited by using an embedded drawing tool, which enables the creation of diagrams and texts. A slide can be zoomed in and out so that the viewer can better see the whiteboard content or students' work, for example. The tool, therefore, can be effective and flexible to represent problems of teaching such as the one illustrated in the previous section. Given a slideshow that represents one such problem, the apprentice can input his or her proposed

\footnotetext{
${ }^{2}$ A research and development project directed by P. Herbst and D. Chazan. ThEMaT stands for Thought Experiments in Mathematics Teaching.
} 
actions through new frames where they might, for example, edit the whiteboard content or add more virtual teacher's dialog. The simulation system could respond to those actions, for example, by modifying virtual students' facial expressions, adding lines of dialog for virtual students, and so forth, thus giving feedback to the apprentice.

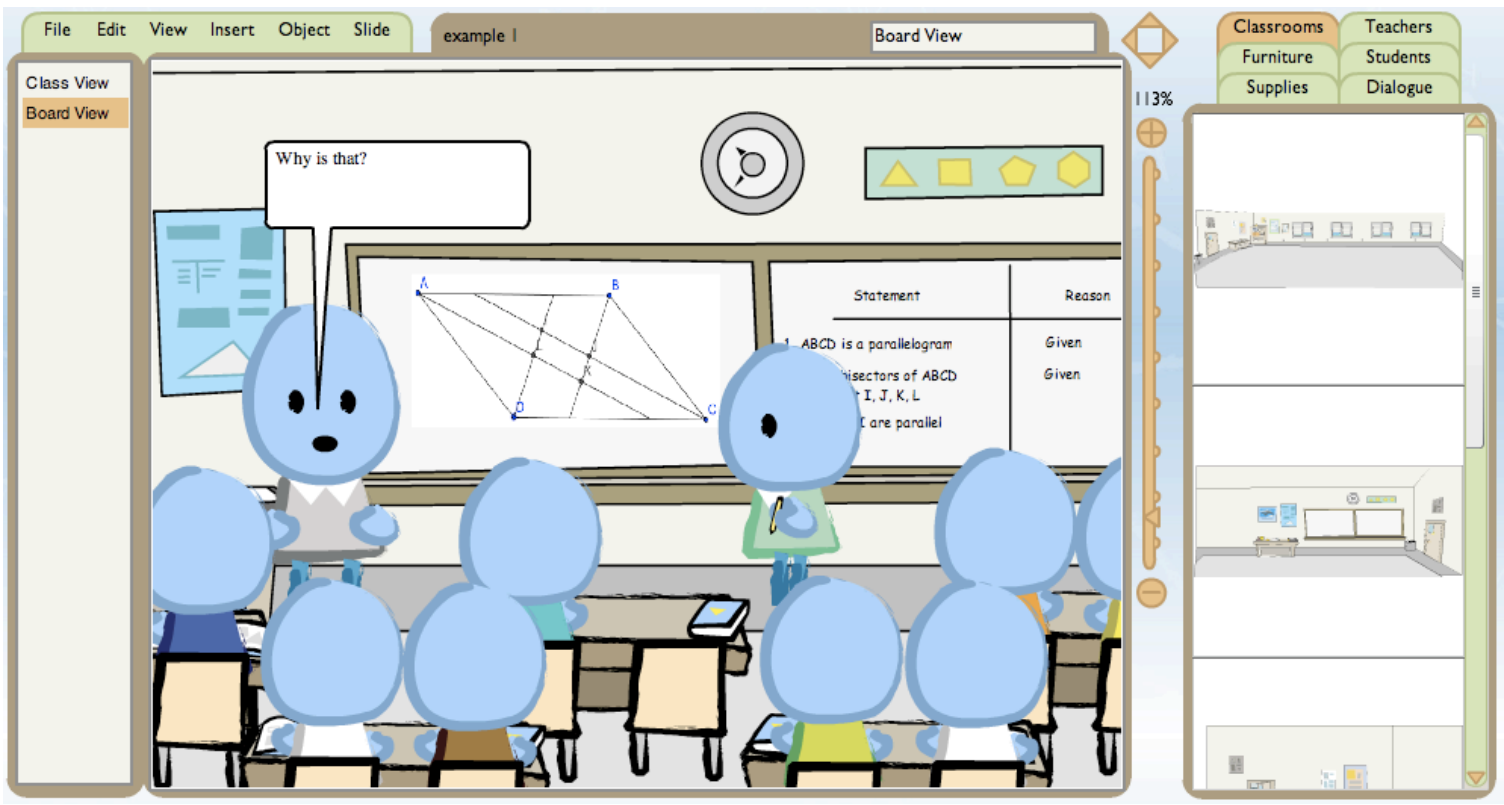

Figure 3. A screen shot of ThEMaT's lesson sketching tool.

Assume that the problem of teaching described in the previous section has been presented to the apprentice using the cartoon-based representation component. The apprentice is expected to say something when Eamonn (a virtual student) seems to be stuck. Imagine that the apprentice, through the virtual teacher, decides to ask Eamonn for a justification by entering a teacher dialog "Why is that?" The diagnosis component of the simulation system uses a knowledge model of teaching expertise (we describe this model in the following section, see also Figure 2) to analyze this decision and try to detect the control(s) that account for the decision made by the apprentice.

The diagnosis result is then sent to the feedback component, which in turn uses a knowledge model of scaffolding techniques in teacher education and teaching expertise to compute the most relevant feedback for the apprentice teacher (we give more details about the diagnosis component and the feedback component in the following sections about learner modeling and feedback modeling). For the time being, we consider four kinds of feedback (Figure 2): (1) reactions of the virtual students expressed in the 
representation component; (2) text-based prompts to encourage the apprentice, for example, to pay attention to his or her instructional objectives; (3) alternative solutions by expert teachers shown in video clips of real classroom interaction, animation clips and slideshows of designed classroom interaction, or text that narrates any of those kinds of classroom interaction; and (4) theoretical resources in the forms of hypermedia web pages that connect categories of questions about the problem of teaching at hand (e.g., students' thinking, teachers' tactics, mathematics) with classroom discourse tactics, student conceptions about geometric figures, functions of proof in mathematical practice, and so on.

When the system detects that the apprentice has been able to manage the teaching task at hand (e.g., how to respond to a student who appears not to know what to do after making a statement when doing a proof) well in that particular problem of teaching, the system moves to other problems of teaching that could happen in the same instructional situation. The iterative process of feedback continues until when the system has evidence that the apprentice has developed the ability to manage a diversity of teaching tasks effectively or when all problems of teaching in the database of the system have been presented to the apprentice.

\section{Theoretical Framework}

Piagetian epistemology (Piaget 1985) has contributed the notion that students learn by adapting their prior knowledge to the feedback provided by the environment that they are confronting. Considering this view of learning as adaptation, Brousseau (1997) contributes the notion of the milieu as a critical element for an instructional theory. In Brousseau's technical sense, the milieu refers to the system counterpart to the learner in an adidactical situation. In particular, the milieu plays a dual role: the target of the actions of the learner and the source of feedback on those actions (Vergnaud 1981). When the apprentice interacts with the teaching simulator described previously, it can generate feedback for the apprentice; the feedback is "computed" and presented to him or her with regard to principles of Brousseau's theory, as described in the following paragraph.

The notion of knowing has been used to refer to the cognitive structures that describe the interaction between a person and an object of knowledge (Brousseau 1997; 
see also Foucault 1972, p. 15). Knowing is different from knowledge which refers to socially shared, explicit intellectual artifacts that are the target of knowing (Cook and Brown 1999). The notions of knowing and conception have been formalized in the context of the ckф (conception, knowledge, and concept) model (Balacheff and Gaudin 2010), whereby conceptions are modeled as quadruplets of problems (P), operators (R) used in the solutions of the problems from $\mathrm{P}$, a representation system (L) enabling the representation of $\mathrm{P}$ and $\mathrm{R}$, and a control structure $(\Sigma)$. Conceptions describe stable spheres of practice that might, in particular, include productions that (from the perspective of a different conception) could be described as errors. The notion of knowing, in turn, identifies a set of related conceptions, for example the different conceptions that might be useful to describe different responses to the same problem. Brousseau's theory of didactical situations is founded on the notion that to learn a new conception the learner may need to locally engage and refute older conceptions that the new conception regards as leading to error (see for example Castela 1995). In our present work the diagnosis component is designed in such a way that it uses a model of teaching expertise and analyzes the apprentice's decisions to model the conceptions behind those decisions. A model of the apprentice's conceptions is critical for the system to be able to generate relevant feedback automatically. By relevant feedback from Brousseau's learning point of view, we mean scaffoldings that help the apprentice understand why his or her knowings in use are correct or erroneous so that s/he can improve how to manage the teaching task at hand.

The knowledge or domain of teaching expertise needs to be represented using computational models for the purpose of automatic feedback. We use the cK $\phi$ model, a computational framework for didactic research (Balacheff and Gaudin 2010) and for developing intelligent tutoring systems (Chieu, Luengo, Vadcard, and Tonetti in press; Webber 2004). The aspect of the cKф model that concerns the design of the teaching simulator is the formalization of a conception. The fourth element, the set of controls, allows the apprentice to decide whether an action is relevant or not, or to realize that a problem or sub-problem is solved (Balacheff and Margolinas 2005). Researchers (e.g., Schoenfeld 1985) have pointed out the critical role of control elements in problem solving and decision-making. Indeed, the apprentice may use the control elements to 
justify the appropriateness of an operator, and the teaching simulator can use them as criteria (i.e., evidence it has about how the apprentice accounts for the controls) for generating relevant feedback.

The $\mathrm{cK} \phi$ model is sometimes insufficient to completely model the problemsolving situation at hand. Chieu, Luengo, Vadcard, and Tonetti (in press) thus introduce a particular kind of variables (i.e., variables that account for the pin position on the X-ray views) to handle that issue. We use task variables, in addition to the $\mathrm{cK} \phi$ elements, to better model the teaching task at hand. A task variable is an important factor of the teaching task at hand; its different values may affect the apprentice's decision-making differently. For example, what a student doing a proof at the board does after making a statement is a task variable because it may have multiple values: the student may give a reason or the student may be unable to give a reason. Depending on what the virtual student does, the apprentice may have different moves. We discuss more about the role of task variables below.

\section{Knowledge Modeling, Learner Modeling, and Learner Diagnosis}

To build the cK $\varnothing$ model for the teaching simulator, we used results from studies of geometry classrooms (Herbst, Chen, Weiss, and González 2009) and results of analysis of teacher discussions about an atypical instance of the situation of "doing proofs" in geometry classrooms (Herbst and Chazan 2003; Nachlieli and Herbst 2009; Weiss, Herbst, and Chen 2009). In that instance, the teacher breached a situational norm (that the teacher needs to see that each statement in a proof is justified by a reason before the next statement in the proof is made) to solve the impasse of having a student silent after making a statement; instead the teacher suggested that the student assumed the statement made for the time being and continued on with the proof. Researchers used teacher discussions of that video to elicit the practical rationality that guides the experienced teachers' usual moves and in particular to learn what they judged could have been done instead or how they would have justified doing what the teacher in the video did. This methodology of engaging teachers in discussions about breached instances of an instructional situation has been the basis of project ThEMaT, in which researchers invited 
experienced teachers to study group conversations in which they watched and discussed animations of classroom interaction that represented breached instances of situations like “doing proofs" (Herbst and Miyakawa 2008). By analyzing teacher conversations while watching and discussing breached norms, the researchers have been able to identify problems, operators, and controls that can be used to model teacher's conceptions that contribute to the work of "doing proofs" in geometry teaching.

Tables 1, 2, and 3 shows examples of the elements of the $\mathrm{cK} \phi$ model and of the task variables we identified for the task of teaching described earlier (to find out what to do when a student is silent after having produced a statement in a proof). To model the conceptions that could account for the apprentice's response to that task, the ck $\not$ model requires us to describe the set of problems that those conceptions might address. One way to do this is by identifying cognitive variables, that is variables whose values might call for different actions or decisions on the part of the agent (Vadcard and Luengo 2005). Cognitive variables are called didactical variables when they can be manipulated by the instructor to produce a change in conception (Brousseau, 1997). For the sake of illustrating our approach, we consider two didactical variables (in the task of teaching at hand) that are at the source of different kinds of teaching problems needed to model conceptions at play (see Table 1). One of those variables is the teacher's role vis-à-vis the student task. This variable has, at least, two values: (1) assisting students in proof production or (2) checking the quality of students' proof production. The other variable is the knowledge at stake in the student task (i.e., the learning objective). This variable has, at least, three values: (1) a specific student's knowledge of how to prove the conjecture; (2) the class's capacity to prove the conjecture; and (3) the class's capacity to produce a specific proof of the conjecture correctly. The combination of those variables yields the list of problems in Table 1. Note that didactical variables are used to present the apprentice with strategic demands whereas task variables (e.g., TV1 and TV2 in Table 1) are used for tactical demands (see more in the discussion section).

Table 1. Examples of problems and task variables.

\begin{tabular}{ll}
\hline P1 & To assist a specific student's production of a proof of a conjecture. \\
P2 & To assist a group of students in the production of a proof of a conjecture. \\
P3 & To assist a student or group of students in producing a specific proof for a conjecture. \\
\hline
\end{tabular}


Accepted for publication at ZDM-The International Journal on Mathematics Education

P4 To check the validity of a proof done by a specific student or a group of students.

P5 To check whether a specific proof has been achieved by a student or group of students.

TV1 What a student doing a proof at the board does after making a statement: giving a reason or being unable to give a reason or assuming the statement to be true and continuing.

TV2 Whether or not the student' statement to be justified is relevant to achieving a proof.

Table 2. Examples of operators.

OP1 The teacher asks: "Why is that?"
OP2 The teacher asks: "Does someone else know why is that?"
OP3 The teacher asks: "What will you say next?"
OP4 The teacher lets the student assume the statement to be true and continue.
OP5 The teacher asks: "Do you really need to prove that those lines are parallel?"
OP6 The teacher says: "The justification is that they are parallel because they make congruent corresponding
OP7 The teacher asks the student to sit down and call another student to continue.
OP8 The teacher asks: "What angles would you need to show congruent to prove that those lines are parallel?"
OP9 The teacher says: "I am sorry Eamonn, let us move on to the next problem because this is too difficult."

To model the conceptions one needs to specify the operators that could be engaged in handling these problems at the moment of figuring out what to do with the student's silence. Table 2 lists examples of those operators. Many of those operators come from the work of Nachlieli and Herbst (2009) who identify various tactical responses to deal with the student's silent, for example, bounce (the teacher challenges the need for the student's statement, see OP5), giveaway (the teacher provides the reason for the statement, see OP6), dismiss (see OP7), scaffold (the teacher gives the students more resources to produce the reason, see OP8), take back (the teacher withdraws the problem, see OP9).

The control structure in cke consists of a set of propositions and proposals that regulate the execution of the solution to a problem and verify the solution arrived at. For the specific task of teaching at hand, we are interested in controls that determine whether an operator may or must be engaged and whether it has been correctly engaged. Herbst et al. (2009) identified a large number of controls for the situation of "doing proofs." As regards the specific task of teaching at hand for the apprentice, the controls could be classified into four main categories (examples in Table 3): (1) situation norms, specific to 
the instructional situation of "doing proofs"; (2) didactical contract norms that define in general the role and responsibilities of the teacher and the students vis-à-vis the knowledge being taught; (3) task norms that include mathematical propositions known as well as knowledge of student conceptions; and (4) professional obligations to four stakeholders (the discipline of mathematics, the students as individuals, the students as a group, and the school institution; see Herbst 2010). The classification of the set of controls could be useful for the system to generate fine-grained feedback for the apprentice. We discuss more about this point in the next section.

We believe that the representation system of graphic-based slides (see also Figure 3 ) that uses 2-D cartoon characters, with variable facial expressions and gestures, and the use of speech bubbles (that can be positioned at will and that can be coded for prosody such as shouting and whispering) to record conversations, recitation patterns of classroom discourse (triadic dialogue) with individual student at the board, and so on is sufficient to represent interactions between the apprentice and the teaching simulator. They compose the semiotic register for the conceptions being modeled.

Table 3. Examples of controls.

\section{Situation norms}

$\Sigma 1$ After a statement in a proof is made and before the next statement is made, the student must provide a reason for the first statement.

\section{Didactical contract norms}

$\Sigma 2$ A mathematical task issued to one student may be issued to any student in the class.

$\Sigma 3$ If a student cannot do a task the teacher may modify the task.

Task norms

$\Sigma 4$ If lines a and b make congruent corresponding angles when they meet line $\mathrm{c}$, then lines a and b are parallel.

$\Sigma 5$ If a child states that two angle bisectors are parallel when he is trying to prove that angle bisectors of a parallelogram make a rectangle, he may be thinking that a rectangle is a parallelogram with a right angle.

\section{Professional obligations}

$\Sigma 6$ Assertions about mathematical objects that are not postulated need to be proved intellectually rather than verified empirically or grasped perceptually (obligation to the discipline of mathematics)

$\Sigma 7$ Individual students are capable to think and reason as well as capable of having cognitive difficulties (individual cognition)

The elements of conceptions described and illustrated above serve the purpose of modeling the apprentice's knowledge. A model of the apprentice's control structure $(\Sigma)$ in 
particular, can help understand on what basis the apprentice would do one or another thing (Schoenfeld 1985). The goal of the diagnosis component is to identify the controls that could be associated to the apprentice's actions (i.e., to make hypotheses about his or her knowings) after each of the decisions s/he makes during his or her interaction with the simulator. Performing such a diagnosis, however, is difficult. For example, when the apprentice takes OP1 (Table 1) the first time, it is difficult to diagnose whether $\Sigma 1$ (Table 3 ) is associated with his or her knowing: he or she may have made such a decision randomly because the control is not associated with his or her knowing, or his or her knowing is associated with the control in a positive manner that might guide him or her to trigger that decision timely. In other words, it is uncertain to diagnose the learner's knowing state (while the presence of a control might recommend a given action, the presence of that given action may or may not attest to the presence of the control) in many situations that are similar to that situation. Bayesian networks are an effective means for modeling uncertain factors (Mayo and Mitrovic 2001). Indeed, Bayesian networks have been proven to be effective in diagnosing the learner's knowing state not only in academic subjects but also especially in complex and ill-structured domains (e.g., orthopedic surgery in project TELEOS) for which it is very difficult to diagnose the learner's practical knowledge.

A Bayesian network is a directed, acyclic graph in which nodes represent random variables and arcs encode conditional dependencies. If there is an arc from node A to another node $\mathrm{B}, \mathrm{A}$ is called a parent of $\mathrm{B}$ and $\mathrm{B}$ is a child of $\mathrm{A}$. A node without parents is a root or unconditional node. A node with parents is called a conditional node, which is associated with a conditional probability table that quantifies the effect of its parents on itself. Researchers often use Bayesian networks to encode probabilistic relationships among variables of interest.

Chieu and associates (in press) advocate that considering the temporal dimension in learner modeling and diagnosis is critical because it may help model the learner's knowing state and cognitive behavior more completely. It is particularly true in the context of professional learning. In orthopedic surgery, for example, even an expert often needs several attempts to be able to arrive at an acceptable solution and s/he often uses the previous unsuccessful actions as adjustment reference to make the next operations. In 
teaching practice, the teacher frequently refers to the reactions of the students to his or her previous moves in order to make the next moves, sometimes to correct unsuccessful moves made earlier. It is hence important to monitor the apprentice's actions and decisions over a period of time to better diagnose the association of the controls with his or her understanding behind his or her decisions. For example, in the above situation both novice and expert teachers may take the same OP1 (the teacher asks: "Why is that?") for the first time, but for the second time the novice teacher may take OP1 again whereas the expert teacher may choose another operation. By considering both moments of decision making (the first time and the second time), the system may be better able to detect that the apprentice needs help and thus produce relevant feedback to help him or her get out of that difficult circumstance. Temporal or dynamic Bayesian networks (Russell and Norvig 2009) can be used to model such a temporal dimension. A temporal Bayesian network is a Bayesian network in which stochastic processes are modeled.

We adapt the Bayesian network technique used in project TELEOS to model teachers' decision making in the context of managing students' doing a proof. We start with the hypothesis that the teacher is working on a given problem (e.g., P2: to assist a group of students in the production of a proof of a conjecture) and a subset of controls that are related to that problem (e.g., $\Sigma 1$ : “After a statement in a proof is made and before the next statement is made, the student must provide a reason for the first statement", and 22: "A mathematical task issued to one student may be issued to any student in the class"). For each control, we identify the task variable(s) and the operator(s) that are related to the control (e.g., TV1: "What a student doing a proof at the board does after making a statement" and OP1 for $\Sigma 1$ and TV1 and OP2 for $\Sigma 2$ ). Those problems, controls, task variables, and operators are used as nodes for the Bayesian network. Finally, we create arcs for the network, mainly from task variables, operators, and problems to the related controls. Figure 4 illustrates a part of the learner model (solid arrows and round-dot arrows are used to only distinguish arcs connected to $\Sigma 1 \_1$ and those connected to $\Sigma 2$ 1, we explain more about those arrows in the following example). The network shown in Figure 4 models two critical moments of decision making by the apprentice to account for the aforementioned temporal dimension: the current moment represented with variables having suffix " 1 " " and the preceding moment represented with 
variables having suffix “_0” (we explain more about this design in the following example). The network is still preliminary at this design phase; we plan to improve and evaluate it both in quantity (number of nodes and arcs) and in quality (structure of the network) at the next phase of implementation.

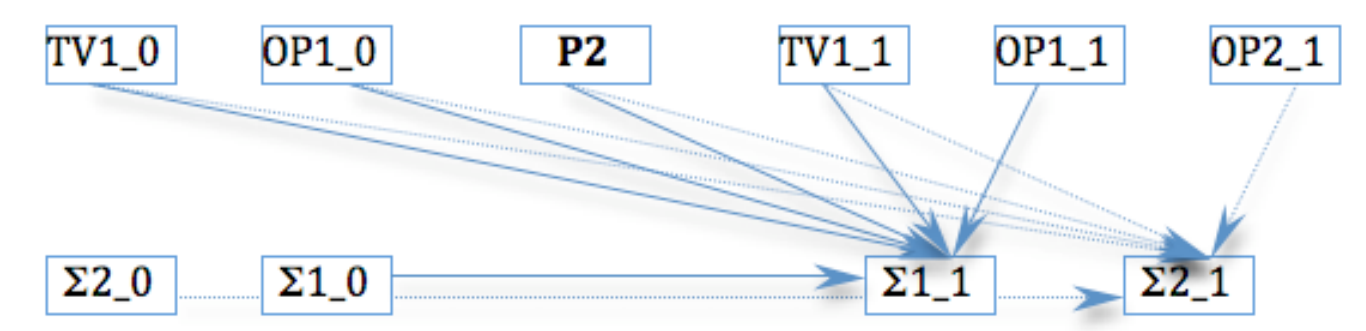

Figure 4. A part of the temporal Bayesian network for modeling the apprentice's decision-making.

For each control, the system can assign one of three states to the association of that control with the apprentice's knowing:

- $\quad$ BPV (brought into play validly): The apprentice's knowing could be associated with the control in a "positive" manner that might allow him or her to trigger the right action in the right context at the right time (the condition is necessary but not sufficient, i.e., if the right action is done one may not be sure that the control exists but one may claim that the control cannot be refuted).

- BPI (brought into play invalidly): The apprentice's knowing could be associated with the control but in a "negative" manner in the current given circumstance, but the association could be "positive" in other circumstances.

- $\quad$ NBP (not brought into play): The apprentice's knowing may not be associated with the control on the basis of the observed actions.

Because there is no evidence about the association of the controls with the apprentice's knowing at the beginning of a problem-solving process, for each control the probability is equally distributed for the three states BPV, BPI, and NBP. The probability of those states is increased or decreased depending on the apprentice's decisions or actions over time. Note that each apprentice has his or her own Bayesian network.

For example, the apprentice deals with P2 (to assist a group of students in the production of a proof of a conjecture) and TV1 at moment 1 (the value of TV1_0 and OP1_0 is set to be undefined at the beginning of the problem-solving process), the value of TV1_1 is that Eamonn is unable to give a reason for his statement. The apprentice 
Accepted for publication at ZDM-The International Journal on Mathematics Education

decides to take OP1 (so the value of OP1_1 is "the teacher asks 'Why is that?"). His or her temporal Bayesian network is updated, for example the conditional probability table of $\Sigma 1 \_1$ is recalculated by taking into account $\Sigma 1 \_0$, TV1_1, and OP1_1 (TV1_0 and OP1_0 are undefined), see the solid arrows in Figure 4, making the probability of BPV (brought into play validly) for control $\Sigma 1$ (after a statement in a proof is made and before the next statement is made, the student must provide a reason for the first statement) increased. It is increased because it seems that the apprentice's knowing is positively associated with $\Sigma 1$, which might guide him or her to ask Eamonn to give a reason (OP1). Suppose that at the next moment (moment 2), however, the apprentice takes OP1 again when Eamonn once again says that he is unable to give a reason for his statement. In this case, by considering the temporal dimension of the decision-making process, meaning that both the previous moment (TV1_0: Eamonn is unable to give a reason, OP1_0: the teacher asks "Why is that?", $\left.\Sigma 1 \_0\right)$ and the current moment (TV1_1: Eamonn is still unable to give a reason, OP1_1: the teacher asks again "What is the reason for your statement?"), and the nature of P2 (see the solid arrows connected to $\Sigma 1_{-} 1$ in Figure 4), the network will increase the probability of BPV for $\Sigma 1$ again, but also increase the probability of NBP (not brought into play) for $\Sigma 2$ (a mathematical task issued to one student may be issued to any student in the class, see $\Sigma 2 \_1$ in Figure 4). The latter is increased because if there were a positive association between the apprentice's knowing and $\Sigma 2$, s/he would take another action, but not OP1 again.

Now assume that another apprentice deals with the same task of teaching, and s/he takes OP1 at moment 1. At moment 2, however, s/he takes OP2 (the teacher asks “Does someone else know why is that?") instead. In this case, his or her temporal Bayesian network will increase the probability of BPV for $\Sigma 2$, because it seems that his or her knowing is positively associated with $\Sigma 2$ in the current teaching task, guiding her to call another student up. Note that the nature of the problem of teaching (P2) is important, for example, if the apprentice were in P1, calling on another student would not be a relevant option.

The above Bayesian network models the apprentice's decision-making process only at two points in time: the current moment and the preceding moment. The apprentice's decisions at other points in time (i.e., before the preceding moment) are 
considered when the network is updated at the preceding moment. More specifically, the control nodes ending with "_0" (e.g., $\Sigma 1_{-} 0$ ) cumulatively represent the diagnosis result of the apprentice's knowings from the beginning of the decision-making process to the preceding moment. In other words, modeling the temporal dimension of the sequence of the apprentice's decisions in the previous Bayesian network could be considered as a means to incrementally construct the learner model: after each of the apprentice's decision, the Bayesian network is updated to account for the system's new diagnosis about the apprentice's current knowing state (see Russell and Norvig 2009, chapter 15).

\section{Feedback Modeling}

Once the diagnosis component updates the probability of the three states of the controls in the apprentice's Bayesian network, it notifies the feedback component about that update. The latter in turn analyzes the diagnosis result in order to produce relevant feedback for the respective apprentice. The main problem is to identify on which specific control(s) among the set of controls the feedback component should focus because after each update, there may be many controls for which the probability of the three states has changed. In addition, there usually are a large number of controls in each subject of tutoring (e.g., over 100 controls in project TELEOS).

In principle, the feedback component selects the controls that are closely related to the current task the apprentice is confronting (i.e., the current problem and task variables, the recent operators taken by the apprentice). Then, among those selected controls the feedback component chooses one or more controls with which the probability of BPI (brought into play invalidly) is highest; if the probability for BPI of two controls are equal, then the probability of NBP (not brought into play) is considered. Finally, the nature of the targeted controls is examined (e.g., on the basis of the categories identified in Table 3) to produce one or more kinds of feedback for the apprentice from the main four types of feedback described earlier: (1) dealing with a new situation presented in the simulator (e.g., reactions from students); (2) reading a prompt or assessing one or several rubrics; (3) exploring alternative solutions; and (4) examining theoretical resources such as pedagogical principles, teaching tactics and strategies, student conceptions, mathematics, and connections among those kinds of resources. The 
first three kinds of feedback can be used if the targeted controls are situation norms or contract norms; the fourth kind of feedback can be used for all types of targeted controls. This feedback technique is based on a number of techniques used in other intelligent tutoring systems (e.g., Mitrovic and Ohlsson 1999; Mufti-Alchawafa and Luengo 2009). Our feedback component slightly differs from others in the classification of controls (which is dependent on the subject being taught, see Table 3) and in the use of semantic networks (Russell and Norvig 2009), as an additional means, to represent many different kinds of resources used for feedback.

For example, if there is no targeted control, the feedback component may adjust the current situation of teaching to probe more the apprentice's knowing state. At moment 1 of the previous scenario, for example, after the apprentice takes OP1 - to ask Eamonn "Why is that?" (an expert teacher may also make this decision in the same situation) - the feedback is to show in the simulation that Eamonn (a virtual student) admits that he is unable to give a reason. By doing so, the system anticipates that the apprentice takes either OP1 again or another action. If s/he takes OP1 again at moment 2, the system has better evidence that his or her knowing may not be associated with $\Sigma 2$ (a mathematical task issued to one student may be issued to any student in the class). Then, by considering the nature of $\Sigma 2$ (a didactical contract norm) the feedback component first pops up a prompt reminding the apprentice of the nature of the problem (P2: to assist a group of students in the production of a proof of a conjecture). If the apprentice is still stuck and asks for more scaffolding, the feedback component may adjust the current scenario by presenting some confused students and an eager student (who might be thinking she may know the reason for the statement). This scaffolding may provide the cues that help the apprentice think about other students in the class and hence decide to call the eager student to the board. If the apprentice still requests more help, the feedback component can ask him or her to watch a video clip of teaching practice by an experienced teacher in a circumstance that is similar to the apprentice's. S/he can also read experienced teachers' comments on the video clip.

If at moment 2 the apprentice takes another action (say OP2: the teacher asks “Does someone else know why is that?"), the feedback component may present a new task of teaching in which a new virtual student (Alice) admits that she can continue to do 
the proof if she can assume that the current statement is true. This new task is useful for teacher learning (Nachlieli and Herbst 2009) because it can destabilize $\Sigma 1$ (after a statement in a proof is made and before the next statement is made, the student must provide a reason for the first statement) by the apprentice. If $\mathrm{s} /$ he does not know what to do next and asks for help, the system may lead him or her to navigate several web resources about mathematical content knowledge, which show how to do the proof in other ways, for example, to prove that each angle of the quadrilateral IJKL (see Figure 1) is a right angle. By reading those resources the apprentice may ask Alice and her peers whether they can try another ways at the proof instead of looking for a justification of the statement they have made. If the apprentice lets Alice assume the statement to be true and to continue to do the proof, the system may ask him or her to examine the alternative stories proposed by experienced teachers apropos of the same scenario (Nachlieli and Herbst 2009). Those comments by experienced teachers help give reasons why one might or might not let Alice make an assumption and continue.

The same scaffolding process is used throughout different problem-solving interactions and sessions, so as to increase the probability of BPV (brought into play validly) for all of controls the system models for the apprentice. We propose that as the criterion for learning by the apprentice. So, that process continues until the system has the evidence that the apprentice is able to use a variety of controls wisely in diverse problems of teaching.

The previous presentation of the feedback component indicates that the system needs to manipulate artifacts and resources in different formats (text, video clips with comments, web pages, etc.) and of different nature (problems, controls, operators, task variables, prompts, alternative solutions, theoretical resources). We believe that semantic networks (Russell and Norvig 2009), an important tool in artificial intelligence to represent computational logic models, could be an effective means to represent different resources and relationships among them.

A semantic network is a directed graph in which nodes represent objects and categories of objects and arcs represent relations among objects. Figure 5 shows a part of the semantic network for the situation described earlier. The labels of categories and of 
relations among objects (e.g., "Student facial expressions", "UsedFor”) are standardized so that the software system can "understand" and search for particular objects.

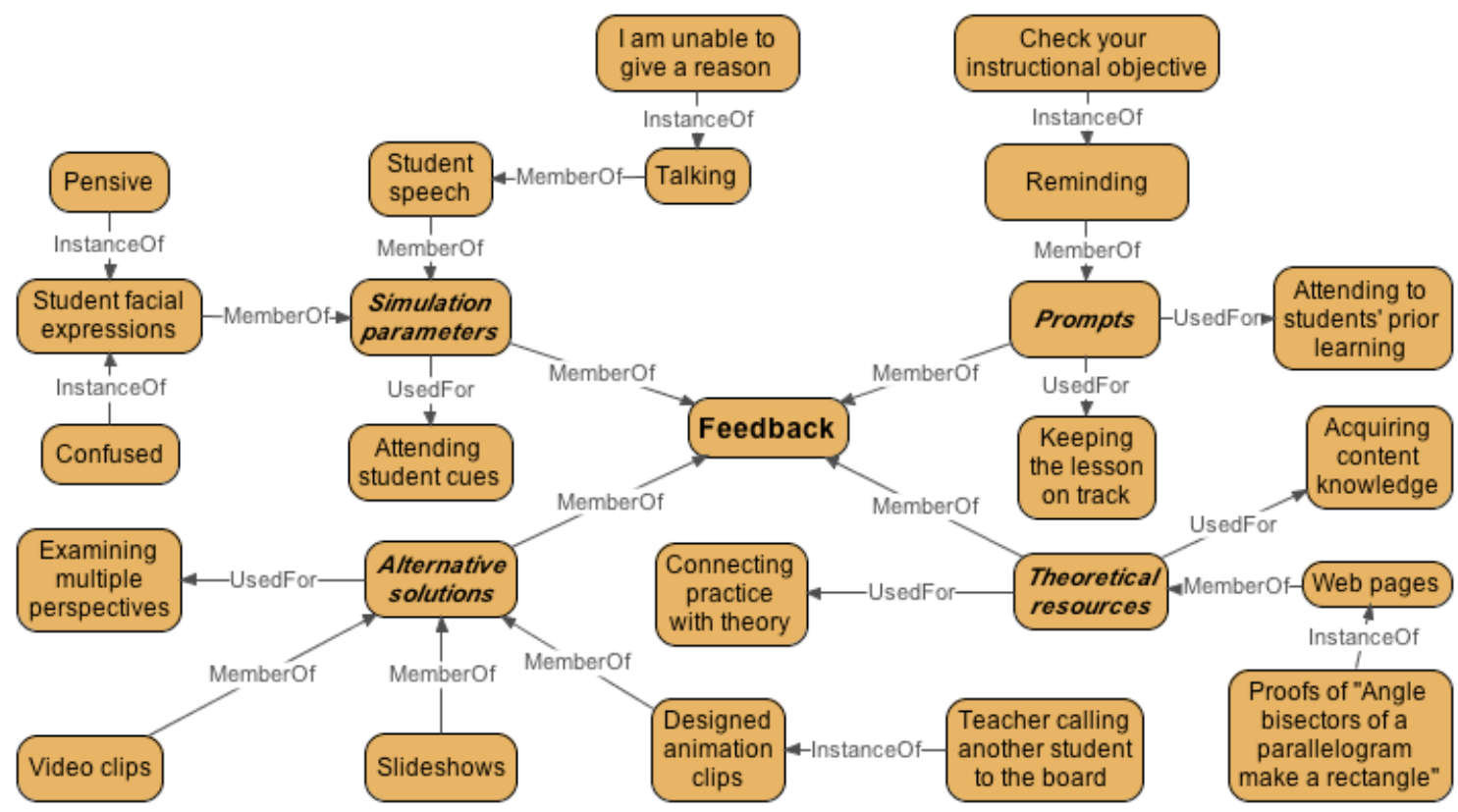

Figure 5. A part of the semantic network for modeling feedback resources.

We have considered the previous four kinds of feedback to build the above semantic network. For example, the category of simulation parameters is used to generate new situations presented in the simulator. If the system searches for a virtual student's spoken words to challenge the apprentice (see the examples described earlier), it can navigate through the sub-category of "Student speech", then "Talking" (or "Shouting"), and choose an instance of the last sub-category, depending on the current interaction between the apprentice and the system. The system can also search for students' facial expressions such as "Confused" in a similar way.

\section{Discussion}

Constructing the knowledge model, the learner model, and the feedback component are keys to implement an intelligent tutoring system. We have identified sample problems, operators, controls, and feedback resources in the situation of managing students doing proofs for those models and component. It would be necessary to enrich that set of elements by extending the review of the literature of research on teaching expertise or even conducting new empirical studies for that purpose. Note that 
the main objective of the diagnosis component is to model collective teaching knowledge of expert teachers and that the main objective of the system is to help the apprentice gradually acquire that collective knowledge.

An important lesson from the design of the teaching simulator described previously is that while teaching is extremely complex, teaching expertise has many dimensions, and creating conditions of learning for the apprentice is very difficult, the artificial intelligence approach gives operational tools to manage that complexity and proceed incrementally to a fine grained theory of teaching. The work presented in this paper shows that modeling even a single teaching task requires a lot of effort. Modeling other teaching tasks may not be as hard as the first one because we can utilize the modeling process, though it still requires a large amount of work for identifying specific elements and models for specific teaching tasks.

Indeed, firstly we relied on the expertise of a group of experienced teachers to identify the controls and operators of the ck $\phi$ model for the instructional situation of doing proofs. The studies of practical rationality in project ThEMaT provided those elements (other studies may be needed for other instructional situations; see Herbst, Nachlieli, and Chazan in press for another example). Then, we identified didactical variables to be able to create a set of problems of teaching (Table 1), as strategic demands for the apprentice. We also created task variables (for the task of the apprentice, see Table 1). The task variables can be used to present various tactical demands to the apprentice and hence help him or her learn how to handle those demands, while accounting for strategic demands. For example, the simulation system deliberately presents the apprentice with the impasse (Eamonn is unable to give a reason for his statement) to try to detect how s/he handles the tactical demand (the impasse) and the respective strategic demand (P2), so as to produce relevant feedback for the apprentice. If Eamonn were able to give a reason, then the system would not be able to detect the apprentice's behavior that is valuable for generating useful feedback. Considering strategic and tactical demands is crucial in problem solving in general (Jonassen 2000) and in teaching practice in particular (Herbst, Chazan, Chen, Chieu, and Weiss this issue). Note that the work of determining the elements of the ck $\phi$ model is dependent on the specific teaching task. 
Another difficult work is the creation and validation of the temporal Bayesian network, especially the identification of relations among ck $\phi$ elements to create arcs of the network. This work is also dependent on the specific teaching task being modeled.

Finally, the work of categorizing the controls to help the system generate relevant feedback and the work of modeling the feedback component are time-consuming and dependent on the specific teaching task as well. The crucial point is to produce feedback that can help the apprentice improve the practice of teaching. The four kinds of feedback presented earlier may make learning happen as follows: When the system presents the apprentice with virtual students' reactions, it tries to help him or her attend to, for example, students' emotions or mathematical conceptions; noticing and interpreting critical events of classroom interactions is important in teacher education (van Es and Sherin 2008). When the system recommends the apprentice to read a prompt or assessing one or several rubrics, it tries to engage him or her in reflecting on his or her decisions; reflection on one's own practical skills is also critical in teacher learning (Hatton and Smith 1995; Schön 1983). When the system encourages the apprentice to explore alternative solutions by expert teachers, it may help him or her examine and evaluate alternative teaching tactics and pedagogy to be able to adapt to various tactical and strategic demands of teaching; Lin, Schwartz, and Hatano (2005) advocate that adaptation is a key skill for successful teaching practice. When the apprentice is engaged in examining theoretical resources, $\mathrm{s} /$ he may have the opportunities to explore and learn about, for example, how to do the proof in other ways.

We also have learned a couple of lessons regarding the artificial intelligence. Firstly, we slightly extended the notion of operator (e.g., the teacher asks "Why is that?") in the $\mathrm{cK} \phi$ model to make a pragmatic use of the model. We might have used general operators such as "asking questions" and make "the teacher asks "Why is that" as a value of the operator. We instead used very specific operators to account for the nature of complexity and specificity of instructional practice (i.e., for the same general operator such as "asking questions", different questions may lead to various problems of teaching that may be really different from each other). Consequently, the Bayesian network for the learner model may be more complex in the case of using specific operators than in the 
case of using general operators, but we believe that it could help the system better diagnose the apprentice's knowing state.

Secondly, the challenge of the use of language in teaching practice (Chazan and Ball 1999; Lobato, Clarke, and Ellis 2005) is critical. For example, to integrate a huge number of web resources for teacher education and development (Fishman and Davis 2006) into our system, it may be necessary to develop the Semantic Web and the ontology, at least for the domain of mathematics teacher education. The Semantic Web "has been proposed as a common language that can ensure that the meaning of each web [page] is represented and available for computer understanding." (Woolf 2009, p. 366). Unlike web search engines that search for keywords that appear in web pages, the Semantic Web would allow users and software systems to make complex requests. Ontology is a system of explicit representations of encoded topics and concepts in a certain domain or sub-domain (Woolf 2009). According to Mizoguchi and Bourdeau (2000) the terminologies used by teachers, practitioners, researchers, authors, and developers differ and must be reconciled. We would need a uniform representation of knowledge (e.g., teaching expertise of mathematics education) and a common vocabulary so that different people and different software systems can communicate to each other more effectively. The ontology systems and semantic networks are core elements for building the Semantic Web successfully.

\section{Conclusion}

We have shown how to use artificial intelligence tools and models to unpack the complexity of the work of teaching and to design a simulation-based intelligent tutoring system that can be used to help the novice teacher improve the practice of teaching. While the specific practices modeled are admittedly narrow, the paper demonstrates an approach to representing teaching with simulations. Obviously taking this approach to a scale that enabled the learning of all of mathematics teaching is a much larger enterprise. The paper does show, however, that interacting with an intelligent teaching simulator may provide the apprentice teacher with a unique experience from a first-person perspective, closer to what s/he does when teaching a real classroom. 
Accepted for publication at ZDM-The International Journal on Mathematics Education

\section{References}

Allen, D.W., \& Eve, A.W. (1968). Microteaching. Theory Into Practice, 7(5), 181-185.

Balacheff, N., \& Gaudin, N. (2010). Modeling students' conceptions: The case of function. CBMS Issues in Mathematics Education, 16, 207-234 (shortened and edited version of Balacheff, N., \& Gaudin, N. (2002). Students conceptions: An introduction to a formal characterization. Grenoble, France: Les cahiers du laboratoire Leibniz, ${ }^{\circ} 65$. Retrieved from http://www-leibniz.imag.fr/LesCahiers).

Balacheff N., \& Margolinas C. (2005). cKф modèle des connaissance pour le calcul de situation didactiques. In A. Mercier, \& C. Margolinas (Eds.), Balises pour la didactique des mathématiques (pp. 1-32). Grenoble, France: La Pensée Sauvage.

Bourdieu, P. (1998). Practical reason. Stanford, CA: Stanford University Press.

Brousseau, G. (1997). Theory of didactic situations in mathematics; Didactique des mathématiques 19701990 (N. Balacheff, M. Cooper, R. Sutherland, \& V. Warfield, Eds. \& Trans.). Dordrecht, The Netherlands: Kluwer Academic Publishers.

Castela, C. (1995). Apprendre avec et contre ses connaissances antérieures. Recherches en didactique des Mathématiques, 15(1), 7-47.

Chazan, D. \& Ball, D. L. (1999). Beyond being told not to tell. For the Learning of Mathematics, 19(2), 2 10.

Chieu, V.M., Luengo, V., Vadcard, L., \& Tonetti, J. (in press). Student modeling in complex domains: Exploiting symbiosis between temporal Bayesian networks and fine-grained didactical analysis. Journal of Artificial Intelligence in Education.

Chieu, V.M., Weiss, M., \& Herbst, P.G. (2009). Using web 2.0 interactive rich-media technologies for mathematics teacher education and development. In I. Gibson, R. Weber, K. McFerrin, R. Carlsen, $\&$ D.A. Willis, Proceedings of the 20th SITE International Conference on Information Technology and Teacher Education (pp. 3619-3624). Chesapeake, VA: Association for the Advancement of Computing in Education.

Cook, S.D.N., \& Brown, J.S. (1999). Bridging epistemologies: The generative dance between organizational knowledge and organizational knowing. Organization Science, 10(4), 381-400.

Fernandez, M., \& Robinson, M. (2006). Prospective teachers' perspectives on microteaching lesson study. Education, 127(2), 203-215.

Fishman, B. J., \& Davis, E. A. (2006). Teacher learning research and the learning sciences. In R. Keith Sawyer (Ed.), The Cambridge handbook of the learning sciences (pp. 535-550). Cambridge, MA: Cambridge University Press.

Foucault, M. (1972). The archaeology of knowledge and the discourse on language. New York, NY: Vintage.

Greeno, J.G. (2006). Learning in activity. In R. Keith Sawyer (Ed.), The Cambridge handbook of the learning sciences (pp. 79-96). Cambridge, MA: Cambridge University Press.

Hatton, N., \& Smith, D. (1995). Reflection in teacher education: towards definition and implementation. Teaching and Teacher Education, 11(1), 33-49.

Herbst, P., Nachlieli, T., \& Chazan, D. (in press). Studying the practical rationality of mathematics teaching: What goes into "installing" a theorem in geometry? Cognition and Instruction.

Herbst, P. (2010, April). What practical rationality is. Paper presented at the Research Presession of the Annual Meeting of the NCTM, San Diego, CA.

Herbst, P., Chen, C., Weiss, M., \& González, G., with Nachlieli, T., Hamlin, M., \& Brach, C. (2009). "Doing proofs" in geometry classrooms. In M. Blanton, D. Stylianou, \& E. Knuth (Eds.), Teaching and learning of proof across the grades: A K-16 perspective (pp. 250-268). New York, NY: Routledge.

Herbst, P., \& Miyakawa, T. (2008). When, how, and why prove theorems: A methodology for studying the perspective of geometry teachers. ZDM - The International Journal on Mathematics Education, 40(3), 469-486.

Herbst, P., \& Brach, C. (2006). Proving and 'doing proofs' in high school geometry classes: What is 'it' that is going on for students and how do they make sense of it? Cognition and Instruction, 24(1), 73122.

Herbst, P., \& Chazan, D. (2003). Exploring the practical rationality of mathematics teaching through conversations about videotaped episodes. For the Learning of Mathematics, 23(1), 2-14. 
Jonassen, D.H. (2000). Toward a design theory of problem solving. Educational Technology Research \& Development, 48(4), 63-85.

Lajoie, S.P., Faremo, S., \& Wiseman, J. (2001). Identifying human tutoring strategies for effective instruction in internal medicine. Journal of Artificial Intelligence in Education, 12, 293-309.

Lampert, M. (2010). Learning teaching in, from, and for practice: What do we mean? Journal of Teacher Education, 61(1-2), 21-34.

Lampert, M. (2001). Teaching problems and the problems of teaching. New Haven, CT: Yale University Press.

Lampert, M., \& Ball, D. L. (1998). Teaching, multimedia, and mathematics: Investigations of real practice. New York, NY: Teachers' College Press.

Leinhardt, G., \& Ohlsson, S. (1990). Tutorials on the structure of tutoring from teachers. Journal of Artificial Intelligence in Education, 2, 21-46.

Lin, X. D., Schwartz, D. L., \& Hatano, G. (2005). Towards teacher's adaptive metacognition. Educational Psychologist, 40, 245-256.

Lin, X. D. (2001). Designing metacognitive activities. Educational Technology Research \& Development, 49(2), 23-40.

Lobato, J., Clarke, D., \& Ellis, A.B. (2005). Initiating and eliciting in teaching: A reformulation of telling. Journal for Research in Mathematics Education, 36(2), 101-136.

Luengo, V., Mufti-Alchawafa, D., Vadcard, L. (2007). Design of adaptive surgery learning environment with bayesian network. Proceedings of the 2007 International Technology, Education and Development Conference (CD publication, ISBN: 978-84-611-4517-1). Valencia, Spain: International Association of Technology, Education and Development.

Macleod, G. (1987). Microteaching: end of a research era? International Journal of Educational Research, 11( 5), 531-541.

Mayo, M., \& Mitrovic A. (2001). Optimising ITS behaviour with Bayesian networks and decision theory. Journal of Artificial Intelligence in Education, 12, 124-153.

Mitrovic, A., \& Ohlsson, S. (1999). Evaluation of a constraint-based tutor for a database language. International Journal of Artificial Intelligence in Education, 10, 238-256.

Mizoguchi, R., \& Bourdeau, J. (2000). Using ontological engineering to overcome common AI-ED problems. Journal of Artificial Intelligence in Education, 11, 107-121.

Mufti-Alchawafa, D., \& Luengo V. (2009). Design implementation and computer validation of didactical decision model in a learning environment for orthopaedic. Paper presented at the 2nd International Workshop on Intelligent Support for Exploratory Environments, in conjunction with the 14th International Conference on Artificial Intelligence in Education, Brighton, The United Kingdom.

Mulgund, S.S., Asdigha, M., Zacharias, G.L., Krishnakumar, K., \& Dohme, J.A. (1995). An intelligent tutoring system for simulator-based helicopter flight training. Proceedings of the 1995 AIAA Flight Simulation Technologies Conference (pp. 121-129). Reston, VA: American Institute of Aeronautics and Astronautics.

Nachlieli, T., \& Herbst, P., with González, G. (2009). Seeing a colleague encourage a student to make an assumption while proving: What teachers put to play in casting an episode of geometry instruction. Journal for Research in Mathematics Education, 40(4), 427-459.

Piaget, J. (1985). Equilibration of cognitive structures. Chicago, IL: University of Chicago Press.

Russell, S., \& Norvig, P. (2009). Artificial intelligence: A modern approach (3rd ed.). Upper Saddle River, NJ: Prentice Hall.

Schoenfeld, A. (1985). Mathematical problem solving. New York, NY: Academic Press.

Schön, D. (1983). The reflective practitioner. New York, NY: Basic Books.

Shavelson, R. (1983). Review of research on teachers' pedagogical judgments, plans, and decisions. The Elementary School Journal, 83, 392-413.

Vadcard, L., \& Luengo, V. (2005). Réduire l'écart entre formations théorique et pratique en chirurgie : Conception d'un EIAH. In P. Tchounikine, M. Joab, \& L. Trouche (Eds.), Environnements Informatiques pour l'Apprentissage Humain (pp. 129-139). Paris, France: Institut National de Recherche Pédagogique.

van Es, E.A., \& Sherin, M.G. (2008). Mathematics teachers' "learning to notice" in the context of a video club. Teaching and Teacher Education, 24(2), 244-276.

Vergnaud, G. (1981). Quelques orientations théoriques et méthodologiques des recherches françaises en didactique des mathématiques. Recherches en Didactique des Mathématiques, 2(2), 215-231. 
Accepted for publication at ZDM-The International Journal on Mathematics Education

Wang, J., \& Hartley, K. (2003). Video technology as a support for teacher education reform. Journal of Technology and Teacher Education, 11(1), 105-138.

Webber, C. (2004). From errors to conceptions - An approach to student diagnosis. In J.C. Lester, R.M. Vicari, \& F. Paraguacu (Eds.), Intelligent Tutoring Systems, Lecture Notes in Computer Science (Vol. 3220, pp. 710-719). Berlin, Germany: Springer-Verlag.

Weiss, M., Herbst, P., and Chen, C. (2009). Teachers' perspectives on 'authentic mathematics' and the twocolumn form. Educational Studies in Mathematics, 70, 275-293.

Woolf, B.P. (2009). Building intelligent interactive tutors: Student-centered strategies for revolutionizing elearning. Amsterdam, The Netherlands: Morgan Kaufmann. 